\title{
Imports, Exports and the Firm Product Scope: Evidence From Turkey
}

\author{
Alessia Lo Turco and Daniela Maggioni \\ Department of Economics and Social Sciences, Università Politecnica delle Marche, Ancona, Italy
}

\section{INTRODUCTION AND BACKGROUND}

$\mathfrak{T}^{1}$ HE evolution of an initial simple economic structure into a complex industrial system made up of several sectors producing increasingly sophisticated goods poses the question on the driving forces behind such a structural change in economic development. Part of the economic literature has pointed at the role of trade in stimulating product innovation, especially in developing countries. On the one hand, Goldberg et al. (2009) show that trade liberalisation has contributed to the Indian manufacturing firms' product scope growth both by making imported inputs cheaper and relaxing technological constraints via access to new imported input varieties. ${ }^{1}$ On the other hand, several studies have documented the importance of exporting for firm product innovation in developed economies (Salomon and Shaver, 2005; Hahn and Park, 2011; Bratti and Felice, 2012). ${ }^{2}$ To the best of our knowledge, though, evidence on developing and emerging economies is missing. Nonetheless, developed countries' buyers could transfer technology, know-how and managerial practices to their developing countries' suppliers (Egan and Mody, 1992; Rauch and Watson, 2003), ${ }^{3}$ who, in turn, can engage in innovative efforts in order to absorb and fruitfully exploit the received technologies and knowledge (Goh, 2005). These mechanisms, indeed, could drive positive effects of exports on innovation in developing economies.

Within this framework, this study provides new firm level evidence on the causal effect of importing and exporting on the introduction of new products and product scope in Turkey. We account for mutual exclusivity of importing and exporting and their possible joint adoption in a multiple propensity score matching (MPSM) setting, by exploiting an original sample of Turkish manufacturing firms, obtained by merging trade, production and balance sheet data.

The availability of detailed firm product level data allows us to directly observe and measure the firm product scope and the scope of new products, that is, products not previously

\footnotetext{
The data used in this work are from the Foreign Trada Data, the Annual Business Statistics and the Production Surveys provided by Turkish Statistical Office (Turkstat). All elaborations have been conducted at the Microdata Research Centre of Turkstat under the respect of the law on the statistic secret and the personal data protection. The results and the opinions expressed in this paper are exclusive responsibility of the authors and, by no means, represent official statistics. We are grateful to TurkStat staff from foreign trade statistics and dissemination departments for their help.

${ }^{1}$ At the industry level for the $27 \mathrm{EU}$ countries, a similar analysis is conducted by Colantone and Crinò (2014) who find that an increase in the variety of imported inputs within a sector determines an increase in the number of domestic products.

${ }^{2}$ With the exception of the Slovenian case, for which Damijan et al. (2010) find no significant effect.

${ }^{3}$ They also often act as a channel for new business opportunities. Egan and Mody (1992, p. 329) write 'When evaluating potential suppliers, virtually all buyers first seek information within their own network [...] The first source of information is the personal judgment of other buyers'. By the same token, Rauch and Watson (2003, p. 1027) note that 'one DC [developed country] buyer may introduce another to a supplier it encountered that makes a product variant that is better suited to the other buyer'.
} 
produced by the firm, as in Damijan et al. (2010) and Hahn and Park (2011). In particular, the use of a very disaggregated product classification allows us to capture both 'radical' innovations - products new for the Turkish market and not only for the firms - and innovations consisting of products new for the firms only. This is an important point since the latter may account for a large part of firm innovative efforts in emergent and developing countries (Pamukcu, 2003) and recent evidence has revealed the prominent role of incremental innovations, compared with path-breaking ones, on a country's growth (Puga and Trefler, 2010).

Compared with the existing firm level literature on trade and innovation, we provide some original contributions.

First, as far as we know, this study is the first attempt to account for the impact of exporting, importing and two-way trading at the same time on firm product portfolio and innovation choices.

Second, the investigation of imports at firm level has the advantage of capturing the effect of the purchase of new foreign products, which is not accountable for by means of the sector level Feenstra's (1994) index adopted by existing evidence on the impact of importing on the firms' product scope (Goldberg et al., 2009).

Third, we focus on the effects of exports of the firms' own products. As a matter of fact, in our data, we are able to separate exports of a firm's own products from carry along trade (CAT), that is exports of goods produced by other manufacturing firms, thanks to the availability of detailed product level trade and production data. Recent firm level evidence on the relevance of CAT (Bernard et al., 2012) in countries' exports, indeed, is confirmed by Turkish data (Lo Turco and Maggioni, 2013a). In principle, both kinds of export activities imply the establishment of network relations with foreign customers and both may, then, be relevant for the introduction process of new products. Nevertheless, based on the discussion above, it is interesting to explore whether benefits accrue from exporting of one's own production. We expect selling one's own produced goods to allow firms to directly benefit and learn from the best practices and the new technologies available in foreign markets and to translate them in their production activity.

Fourth, we provide a methodological contribution to the empirical analysis of trade effects at the firm level. We allow for multiple trade options available to firms by means of MPSM. This setting is expected to convey some insights into the relative importance of importing and exporting for developing new products and expanding the product scope. By comparing the findings to the ones from single propensity score matching (SPSM), where export and import entry are considered as isolated strategic decisions, we show that neglecting the possibility of the joint entry into importing and exporting can deliver misleading results and policy implications from empirical studies.

Finally, to the best of our knowledge, this is the first study dealing with the causal impact of trade on the product scope and innovation in Turkey. ${ }^{4}$ The Turkish emergent economy is one of the most rapidly growing across the world. The country is characterised by a highly dynamic manufacturing sector ${ }^{5}$ and, thus, can be considered an interesting case to analyse.

\footnotetext{
4 Only Pamukcu (2003) has analysed the role of trade liberalisation and of machinery imports on Turkish firms' innovation probability, capturing both product and process innovation for the period 1989-93. He finds a positive correlation between imported machinery and the firm innovation propensity, without dissecting any causal relationship, though.

5 According to World Development Indicators, after the 2001 crisis and until 2008, Turkey experienced annual GDP growth rates between 5 and 9 per cent. GDP was then stagnant in 2008 and declining in 2009 , but in 2010, the economy rapidly recovered again and grew by a rate of 9 per cent.
} 
If firm international activities affect its product portfolio choices, it is likely that such effects can be disclosed within the Turkish economy, which is recently experiencing rapid changes in its trade and economic structure (WTO, 2012).

Anticipating our main findings, we highlight the prominence of produced exports in spurring firm product scope and innovation. Importing only reinforces this effect when it is jointly undertaken with exporting. Exporting and two-way trading also foster product quality upgrading.

The work is structured as follows: Section 2 presents data sources and some descriptive statistics on the outcome variables of our study; Section 3 discusses our empirical strategy, results and some robustness checks, Section 4 summarises and discusses the main findings, and Section 5 concludes.

\section{THE DATA}

\section{a. Data Sources and Sample}

To proceed in the exploration of the causal effect of imports and exports on the firm product scope, we focus on manufacturing firms with at least 20 employees for the period 200509. We merge the Turkish Structural Business Statistics (SBS) and Foreign Trade Statistics (FTS) databases by firm, thus gathering information on trade by product at the 12-digit Gümrük Tarife Istatistik Pozisyonu (GTIP) level and on firm revenues, input costs, employment, investment activity, the primary 4-digit NACE (rev 1.1) sector of activity and the region of location for all the firms included in the SBS. Second, we match the resulting dataset with information of 10-digit PRODTR products produced by each firm with more than 20 persons employed contained in the Annual Industrial Product Statistics (AIPS). The latter database allows us to compute the firm product scope and identify the firm introduction of new products. In the following analysis, we define as good a 10-digit PRODTR product. ${ }^{6}$

Also, from the AIPS database, we can detect the export flows of goods that the firm indeed produces. To identify produced exports, for each firm, we matched foreign trade and production flows at product level by exploiting the correspondence table between GTIP trade and PRODTR production codes, provided by TurkStat. ${ }^{7}$

\section{b. Definition of Treatments and Outcomes}

Our empirical strategy rests on the propensity score matching (PSM) approach which is based on the following treatment definitions: starting to import only, starting to export only, starting to export and import (or two-way starting). Then, we define an export (import/twoway) starter as the firm that exports (imports/exports and imports) in $t$ and did not do it in the previous year, that is $t-1$, thus following the existing empirical contributions on the topic (Damijan et al., 2010; Hahn and Park, 2011). According to this definition and to the combination of PSM with the difference-in-differences (DID), estimator we end up with three different waves - years 2007, 2008 and 2009 - of import, export and two-way starters.

\footnotetext{
${ }^{6}$ According to this product definition, multiproduct firms account for 40 per cent of our sample, and this share is stable regardless of the detail $-10,8$ or 6-digit PRODTR codes - of the product definition, while only 14 to 16 per cent of firms are multisector, that is, operate in more than one 2-digit codes.

${ }^{7}$ The matching between firm foreign trade and production data at product level follows the Pierce and Schott's (2009) code harmonisation procedure. Details are available upon request.
} 
Our focus is to look for the causal nexus between a firm's trade, its product range and its ability to innovate. In this respect, an increase in the number of products the firm produces implies the introduction of new 10-digit products. Nevertheless, even in the absence of any increase in the product scope, innovation may occur through the substitution of new for old products. Then, we will explore the effect of starting to export and import on the following outcomes:

- Product scope

$N$ denoting the firm product scope, measured as the number of products produced by the firm;

$P r_{\text {grow }}$ representing a dummy variable equal to 1 if the firm increases its product scope, and 0 otherwise.

\section{- Product innovation}

$N_{\text {new }}$ denoting the firm new products, measured as the number of products that firms introduce in $t$ and did not produce before;

$P r_{\text {new }}$ representing a dummy variable equal to 1 if the firm introduces a new product, and 0 otherwise.

The former pair of variables measures firms' product scope, while the latter captures the extent of product innovation. Our product innovation definition includes products that are new only to the firm and to the whole Turkish economy. The latter can be considered as 'radical' innovations, and, in our sample, they account for about 2 per cent of new products introduced by Turkish firms, while the share of radical innovators is about 0.3 per cent of firms. A detailed empirical analysis of the impact of trade on this type of product innovations is thus prevented by the limited extent of the phenomenon in our data. Nonetheless, the broader definition of product innovation that we adopt allows to capture a large share of firms' innovative efforts in the Turkish emergent economy (Pamukcu, 2003). Incremental innovations determine the growth of domestic product varieties and their spatial diffusion across regions within a country. Indeed, recent evidence has shown that they are of primary relevance for countries' economic growth (Puga and Trefler, 2010).

Table 1 shows the time evolution of our outcomes. The firms' average number of produced goods is slightly above 2, and about 10 to 12 per cent of firms yearly expands their product scope. The average number of new products is rather low and corresponds to less than one fifth of the average product scope, while about 15 to 20 per cent of firms are product innovators. The difference between the probability to expand the product range, $P r_{\text {grow }}$, and the probability to introduce a new product, $P r_{\text {new }}$, discloses that a non-negligible fraction of firms when changing the product mix do, indeed, replace some old products. No particular pattern across years can be detected in our outcomes. Mainly, it is interesting to observe that 2009 - when the global crisis has mostly affected the Turkish economy (Uygur, 2010; Misch and Seymen, 2012; Lo Turco and Maggioni, 2014) - does not display any peculiarity for our variables of interest.

Turning to firms' international activities, importers represent more than half of firms in our sample, and, whereas overall exporters cover the same percentage, exporters of their own products account for the 33 per cent of the sample. As mentioned above, our main interest is the exports of produced goods, so from now on, this will be the definition of exporting adopted in our study. 
TABLE 1

Product Scope and Product Innovation of Turkish Manufacturing Firms

\begin{tabular}{|c|c|c|c|c|}
\hline \multirow[t]{2}{*}{ Year } & \multicolumn{2}{|c|}{ Product Scope } & \multicolumn{2}{|c|}{ Product Innovation } \\
\hline & $\begin{array}{l}\text { Mean N } \\
\text { (1) }\end{array}$ & $\begin{array}{l}\mathrm{Pr}_{\text {grow }} \% \\
\text { (2) }\end{array}$ & $\begin{array}{l}\text { Mean } N_{\text {new }} \\
\text { (3) }\end{array}$ & $\begin{array}{l}P r_{\text {new }} \% \\
\text { (4) }\end{array}$ \\
\hline 2007 & 2.159 & 11.34 & 0.371 & 19.54 \\
\hline 2008 & 2.185 & 10.14 & 0.265 & 14.8 \\
\hline 2009 & 2.279 & 12.16 & 0.280 & 15.27 \\
\hline
\end{tabular}

Notes:

(i) $N, N_{\text {new }}, P r_{\text {grow }}$ and $P r_{\text {new }}$ are defined in the text.

(ii) Columns (1) and (3) report unconditional means, while the remaining columns display percentage shares over the firms' sample.

Source: Our elaborations from Annual Industrial Product Statistics.

To highlight whether trading firms outperform non-trading firms in terms of product scope and innovation performance, we regress our outcomes on two dummies capturing the firm's import and export status (Wagner, 2007). We control for firm size - measured by the log of firm employment - region, sector and time fixed effects. We estimate pooled poisson model ${ }^{8}$ for $N$ and $N_{\text {new }}$ and a pooled probit for $P r_{\text {grow }}$ and $P r_{\text {new }}$. The premia shown in Table 2 reveal that, when alternatively included in the regression, both importing and exporting one's own produced products are positively related to the firm product scope and the number of new products. Importing is not significant for the probability to increase the product scope and introduce new products. However, when both trade activities are taken into account at the same time, the firm import status stays significantly positive only for the product scope and turns negative for the probability to increase the number of produced goods and to introduce new products.

This preliminary investigation suggests to account simultaneously for both firm internationalisation strategies. However, detection of the causal impact of trade on innovation is addressed in the following section.

\section{EMPIRICAL STRATEGY}

To allow for multiple options available to firms willing to trade, we adopt a MPSM framework (Lechner, 2001, 2002). The latter is tailored to consider that firms may undergo several treatments at the same time and that importing and exporting can also represent mutually exclusive strategies. We thus have four mutually exclusive states: the no treatment case that is never importing and never exporting; start importing only; start exporting only; start both importing and exporting. Then, we calculate a full set of average treatment effects on the treated (ATT) for each treatment:

$$
\gamma_{a, b}^{\mathrm{MPSM}}=E\left(Y_{\text {post }}^{a} \mid S=a\right)-E\left(Y_{\text {post }}^{b} \mid S=a\right)
$$

\footnotetext{
${ }^{8}$ Evidence does not substantially change when a negative binomial is used. Results are not shown for brevity and are available upon request.
} 
TABLE 2

Import and Export Premia

\begin{tabular}{|c|c|c|c|c|c|c|}
\hline \multirow{2}{*}{$\begin{array}{l}\text { Product } \\
\text { Scope } \\
\text { Exporter }\end{array}$} & \multicolumn{3}{|c|}{$N$} & \multicolumn{3}{|c|}{$P r_{\text {grow }}$} \\
\hline & $\begin{array}{l}0.231 * * * \\
{[0.014]}\end{array}$ & & $\begin{array}{l}0.222 * * * \\
{[0.014]}\end{array}$ & $\begin{array}{l}0.043 * * * \\
{[0.004]}\end{array}$ & & $\begin{array}{l}0.046^{* * *} \\
{[0.004]}\end{array}$ \\
\hline Importer & & $\begin{array}{l}0.095 * * * \\
{[0.014]}\end{array}$ & $\begin{array}{l}0.040 * * * \\
{[0.015]}\end{array}$ & & $\begin{array}{c}0.000 \\
{[0.004]}\end{array}$ & $\begin{array}{c}-0.010^{* *} \\
{[0.004]}\end{array}$ \\
\hline Observations & 31,499 & 31,499 & 31,499 & 29,092 & 29,092 & 29,092 \\
\hline LL & $-55,338.7$ & $-55,673.8$ & $-55,329.4$ & 0.046 & 0.04 & 0.047 \\
\hline Wald $\chi^{2}$ & $4,734.462$ & $4,096.422$ & $4,743.383$ & 932.547 & 795.783 & 937.97 \\
\hline $\begin{array}{l}\text { Product } \\
\text { Innovation }\end{array}$ & & $N_{\text {new }}$ & & & $P r_{\text {new }}$ & \\
\hline Exporter & $\begin{array}{l}0.337 * * * \\
{[0.039]}\end{array}$ & & $\begin{array}{l}0.328 * * * \\
{[0.040]}\end{array}$ & $\begin{array}{l}0.047 * * * \\
{[0.005]}\end{array}$ & & $\begin{array}{l}0.049 * * * \\
{[0.005]}\end{array}$ \\
\hline Importer & & $\begin{array}{l}0.122 * * * \\
{[0.040]}\end{array}$ & $\begin{array}{c}0.045 \\
{[0.041]}\end{array}$ & & $\begin{array}{c}-0.001 \\
{[0.005]}\end{array}$ & $\begin{array}{c}-0.012 * * \\
{[0.005]}\end{array}$ \\
\hline Observations & 29,092 & 29,092 & 29,092 & 29,092 & 29,092 & 29,092 \\
\hline $\mathrm{LL}$ & $-22,219.1$ & $-22,324.1$ & $-22,217.4$ & 0.046 & 0.042 & 0.046 \\
\hline Wald $\chi^{2}$ & $1,860.802$ & $1,717.028$ & $1,897.441$ & $1,072.584$ & 988.819 & $1,076.517$ \\
\hline
\end{tabular}

Notes:

(i) Size, Region, Sector and Time dummies are included in the regressions but not shown.

(ii) Estimates for $N$ and $N_{\text {new }}$ are from poisson regressions, while estimates for $P r_{\text {grow }}$ and $P r_{\text {new }}$ are from probit regressions.

(iii) For $\operatorname{Pr}_{\text {grow }}$ and $P r_{\text {new }}$, marginal effects are reported.

(iv) $* * * p<0.01$ and $* * p<0.05$. Robust standard errors in brackets are clustered by firm.

where $Y_{\text {post }}$ is the outcome after the treatment ${ }^{9}$ and $S$ represents the status of the firm in terms of the two treatments, $a$ and $b$. The parameter in 1 denotes the expected (average) effect of treatment $a$ relative to treatment $b$ for a participant drawn randomly from the population of firms undergoing treatment $a$.

To account for the possibility that selection into the treatment rests on time invariant unobservable characteristics that are not captured by the matching procedure, we combine the latter with the DID estimator (Blundell and Costa Dias, 2000, 2009):

$$
\gamma_{a, b}^{\mathrm{MPSM}-\mathrm{DID}}=\left[E\left(Y_{\mathrm{post}}^{a} \mid S=a\right)-E\left(Y_{\mathrm{pre}}^{a} \mid S=a\right)\right]-\left[E\left(Y_{\mathrm{post}}^{b} \mid S=a\right)-E\left(Y_{\mathrm{pre}}^{b} \mid S=a\right)\right],
$$

where $Y_{\text {pre }}$ denotes the outcome before the treatment.

As $E\left(Y_{\text {post }}^{b} \mid S=a\right)$ is not actually observable, the missing counterfactual situation after the treatment is proxied by the outcome of the matched controls, selected from the population of firms in the comparative status $b$. It is worth highlighting that in the following section, we compute DID-ATTs for $P r_{\text {grow }}$ (DID $P r_{\text {new }}$ ) by comparing the average value assumed in treated and controls of a dummy equal to one if the firm increased its product scope (introduced new products) after the treatment, but it did not increase its product scope (introduced new products) in the year before the treatment; in all other cases, the dummy assumes value zero.

\footnotetext{
9 Due to the short panel data at our disposal, in the computation of these effects, we focus on the year of the firm entry in foreign markets, $t$, and one year after the entry, $t+1$.
} 
Also, in order to ease ATT effects interpretation in terms of percentage changes, in the analysis, we take the $\log$ of outcomes $N$ and $N_{\text {new }}$.

Each participant receives just one treatment, and the remaining ones all constitute possible counterfactuals. Thus, we compute, for each variable of interest, ATT effects for each of the following pairs: ${ }^{10}$

- Export starters/never traders;

- Import starters/never traders;

- Two-way starters/never traders;

- Two-way starters/export starters;

- Two-way starters/import starters;

- Import starters/export starters;

where the first group of firms represents the treated ones, while the second group is the set of control firms selected on the basis of the estimated propensity scores of the four possible states. The latter are retrieved from the estimation of a multinomial logit model of the start of an internationalisation strategy. In the model specification, we include the first lag of the following variables as regressors: the $\log$ of employment, $l$, the $\log$ of output, $y$, the $\log$ of labour productivity (value added over number of employees), $l p$, a dummy for multiplant firms, multi, the log of the firm average wage (the ratio between total labour costs and number of employees), $w$, and a complete set of two-digit sector, year and regional dummies. ${ }^{11}$ Using the estimated propensity scores, we then apply the 'nearest neighbour' (NN) matching on the 'common support' that consists of matching a starter with the single control ${ }^{12}$ having the most similar propensity score. The matching is implemented cross-section by cross-section; thus, each treated is compared with a control unit in the same year. For each treatment, we will present ATT coefficients, analytical standard errors (Lechner, 2001) and bootstrapped standard errors based on 250 replications (Caliendo and Kopeinig, 2008); we then report the number of treated units and the number of matched control units for both $t$ and $t+1$.

Propensity score matching techniques have been developed to identify causal treatment effects in non-experimental data. The credibility of this approach importantly relies on a rigorous control group selection on the basis of observable variables so that, after matching, any difference between treated and controls in the probability to undergo the treatment is random. The use of matching estimator in combination with difference-in-difference approach can importantly improve the quality of results from nonexperimental settings, as it accounts for time invariant unobservables driving selection into the treatment (Blundell and Costa Dias, 2000). This feature further strengthens the interpretation of ATTs as causal effects. In this respect, however, the implementation and assessment of PSM diagnostics become fundamental. The standard testing procedures confirm the validity of our matching strategy.

\footnotetext{
10 Theoretically, it would be possible to analyse a larger set of treatment combinations, for example 'export starters only versus two-way starters' where the control group consists of two-way starters. However, this would lead us to select the matched controls in a very small sample and to use the same control units several times since the number of treated is much larger than the number of untreated. This would lead to bad-quality matching, and we have preferred to ignore these cases. Finally, we ignore the comparison of the impact of export market entry for import starters as it represents the specular case to the comparison of import starters only with export starters only.

11 Estimation results are available from the authors upon request.

12 Also, the matching is applied 'with replacement': the same control firm may be used as a match more than once.
} 
In particular, the upper panel of Table A1 in the Appendix shows that the matching quality is satisfactory for all of our treated groups: we obtain a relevant drop in the median standardised bias for all investigated comparisons, and the share of treated firms out of support is very low.

This overall picture is rather consistent with evidence of balancing property being satisfied for all of the variables in most pairs of comparison groups, especially when the control group is made up of never traders. In addition, the propensity score distributions of treated and controls overlap after matching. Results are not shown for brevity, but they are available from the authors upon request.

\section{a. Baseline Results}

Tables 3 and 4 show the ATT results for the NN MPSM: in Table 3, we focus on the comparison between export, import and two-way starters versus never traders, while in Table 4, we explore the switching across different trade options.

Table 3 reveals the primary importance of the export activity. Starting to export has a strong and direct impact on both product scope and product innovation. ATT effects are, indeed, positive and significant for all of our variables of interest when we compare export starters with domestic firms. Only at time $t+1$, most of the effects lose their significance, but this could stem from the restricted sample we are left with.

It emerges that starting to export one's own produced goods increases the number of products by 18 per cent in the entry year and by 14 per cent the year after and boosts the probability to expand the product scope by about 6 per cent in $t$. These effects are confirmed by DID-ATTs. The effects on the probability to start expanding the range of products (DID $\left.P r_{\text {grow }}\right)$ are equal to 8.1 per cent at time $t$.

Export entry also spurs the introduction of new goods at time $t$ by increasing the number of new products by 20 per cent and the probability to introduce a new good by 9.1 per cent. When focusing on DID-ATTs, it emerges that export starters have a higher probability to start innovating in both $t$ (9.8 per cent) and $t+1$ (6.4 per cent). Thus, they are more likely to become innovators in the period after their foreign market entry.

As far as imports are concerned, no significant effect emerges from our MPSM estimates. Firms entering the export and import market at the same time, instead, are more likely to both produce new goods and become innovators. These ATT effects are higher than the effects estimated on the sample of new exporters against never traders, discussed above. This suggests that some complementarity may exist between export and import activities. With respect to the possibility of entering the export market only, a domestic firm that starts to both import and export will benefit from a higher innovation rate and a larger product scope.

The analysis of switching across different trade strategies in Table 4 conveys a clear message: starting to export could stimulate innovation in the importing firm that switches to twoway trading. Differently, adding the import activity would not substantially improve the innovation activity of the exporting firms even if these mild effects may be driven by the small sample we investigate. Finally, moving from being an export starter to being an import starter substantially and significantly reduces the firm innovation propensity and its product scope, again confirming that only exporting is rewarding for the firm in terms of innovative outcomes. As this set of results confirms the insights gathered from Table 3, in the remainder of the paper, for the sake of brevity, we will only focus on the comparison between trade starters versus never traders. 


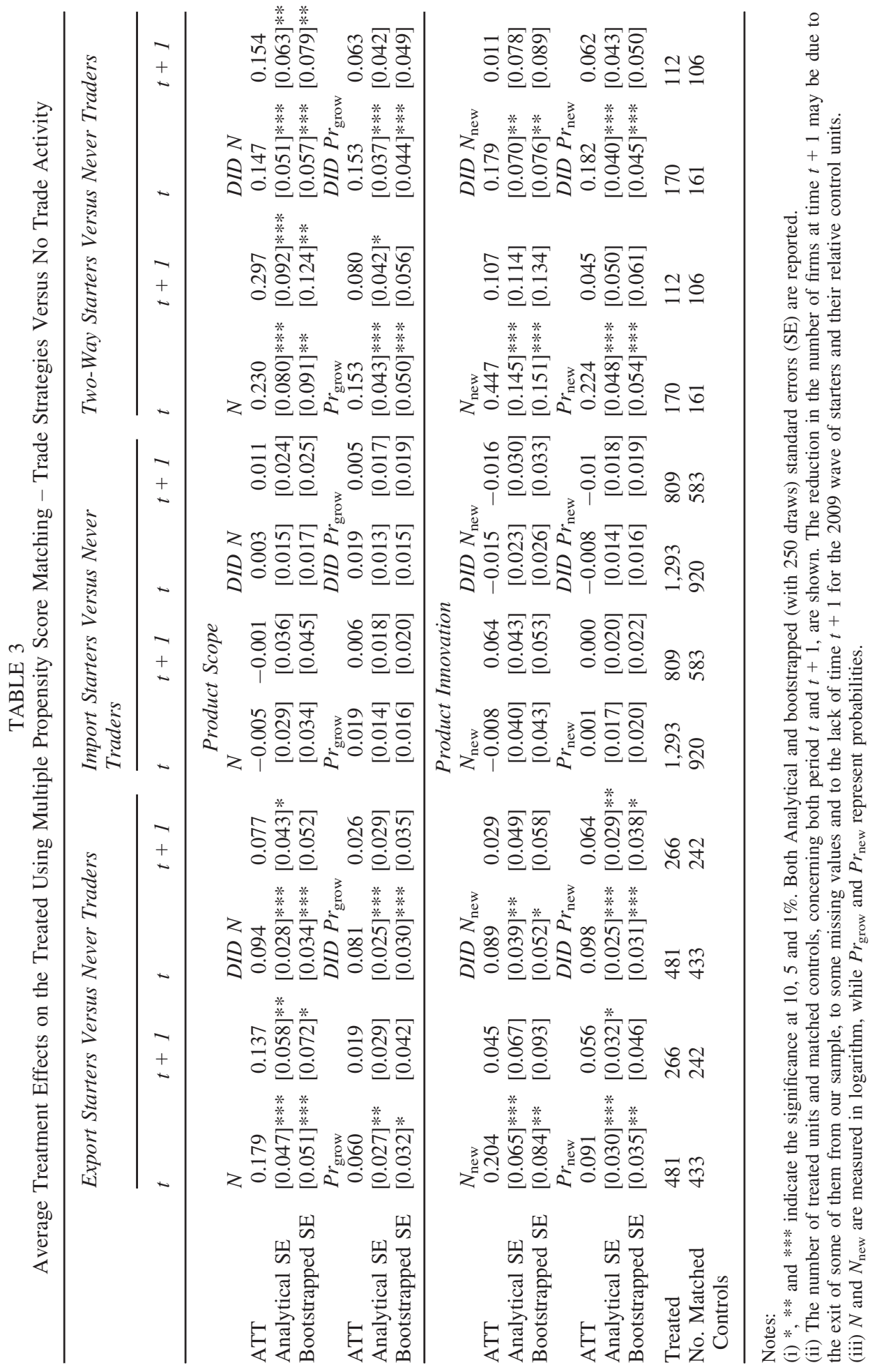




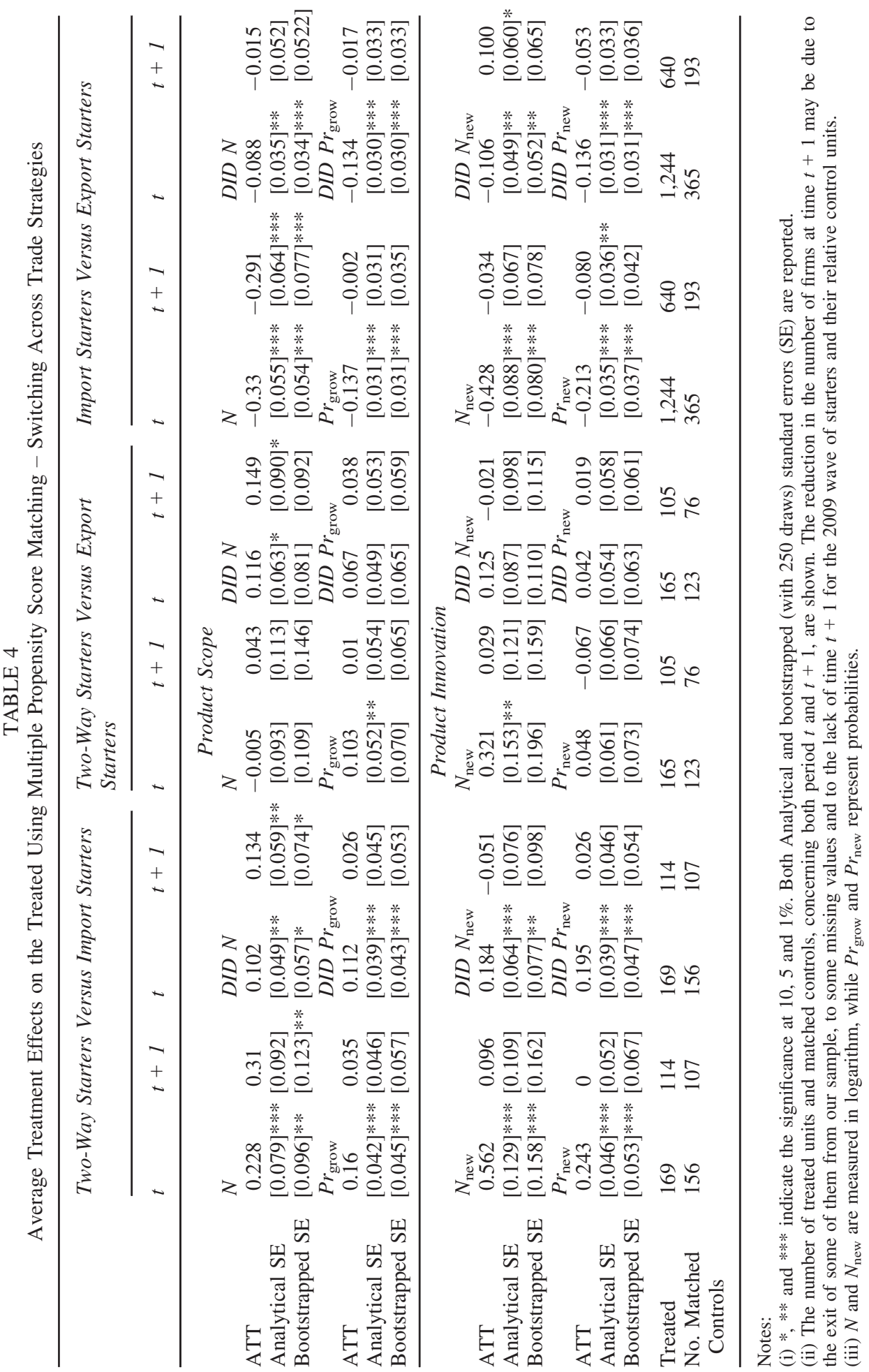


Then, from our findings, product innovations mostly appear to stem from the relationship with foreign customers, and this effect is enhanced when the firm also sources part of its inputs abroad. On the contrary, the use of foreign intermediates alone does not spur the firm's innovative outcomes. Also, much of the action occurs between $t-1$ and $t$, that is the same year the firm enters the foreign market. ${ }^{13}$

In the following, we first highlight the advantage of using MSPS in firm level analysis of trade effects, and then, we move to the identification and deeper inspection of the nature of our main results.

\section{b. Comparing MPSM to SPSM}

In our view, the MPSM approach constitutes an improvement in the empirical firm level analysis of trade compared with the SPSM binary treatment case that has usually been adopted in the empirical assessment of importing and exporting. As a matter of fact, in the binary treatment, case status $a$ basically corresponds to either export or import starting and status $b$ corresponds to either never exporting or never importing. Thus, for each variable of interest, the ATT effect is calculated, for exporting, by comparing:

- Export starters/never exporters;

and, for importing, by comparing:

- Import starters/never importing;

Thus, the main difference between the control group in SPSM and the control group in MPSM is that firms belonging to the former group could be starting to import (export) at the same time or could also be already involved in the import (export) activity. In empirical studies, the latter occurrence is usually accounted for by means of the inclusion of the past import (export) experience in the empirical model for the probability to start to export (import) from which the propensity scores for the selection of control group are recovered. Nevertheless, SPSM leaves aside the possibility to account for the fact that firms defined as export starters and never exporters in $t$ may actually start to import at the same time and the same goes for the definition of the import treatment. Thus, to test the superiority of MPSM, we run a standard SPSM analysis. Besides firm level controls previously included in the multinomial logit specification, we add a dummy for the previous firm exporting (importing) activity as additional regressor in the probit model for the import (export) start. ${ }^{14}$

The left-hand side of Table 5 shows that when we compare import starters to never importers with a similar export experience, importing does not significantly affect firm product scope, while a mild positive impact emerges on product innovation. Purchasing foreign inputs only slightly helps firms to introduce new goods, even if this effect turns out to be non-significant for DID parameters. On the contrary, a firm's exports of its own products strongly affect firm product mix and innovative performance. In particular, it is important to notice that export entry effects are very significant in $t+1$ too. This suggests that in MPSM, the lack of any significant effect after entry is possibly driven by the small sample size.

\footnotetext{
13 This could reveal that firms get prepared to export and product innovation may actually be an anticipated effect of exporting (Van Beveren and Vandenbussche, 2010).

14 The high quality of the matching is confirmed in the lower panel of Table A1.
} 


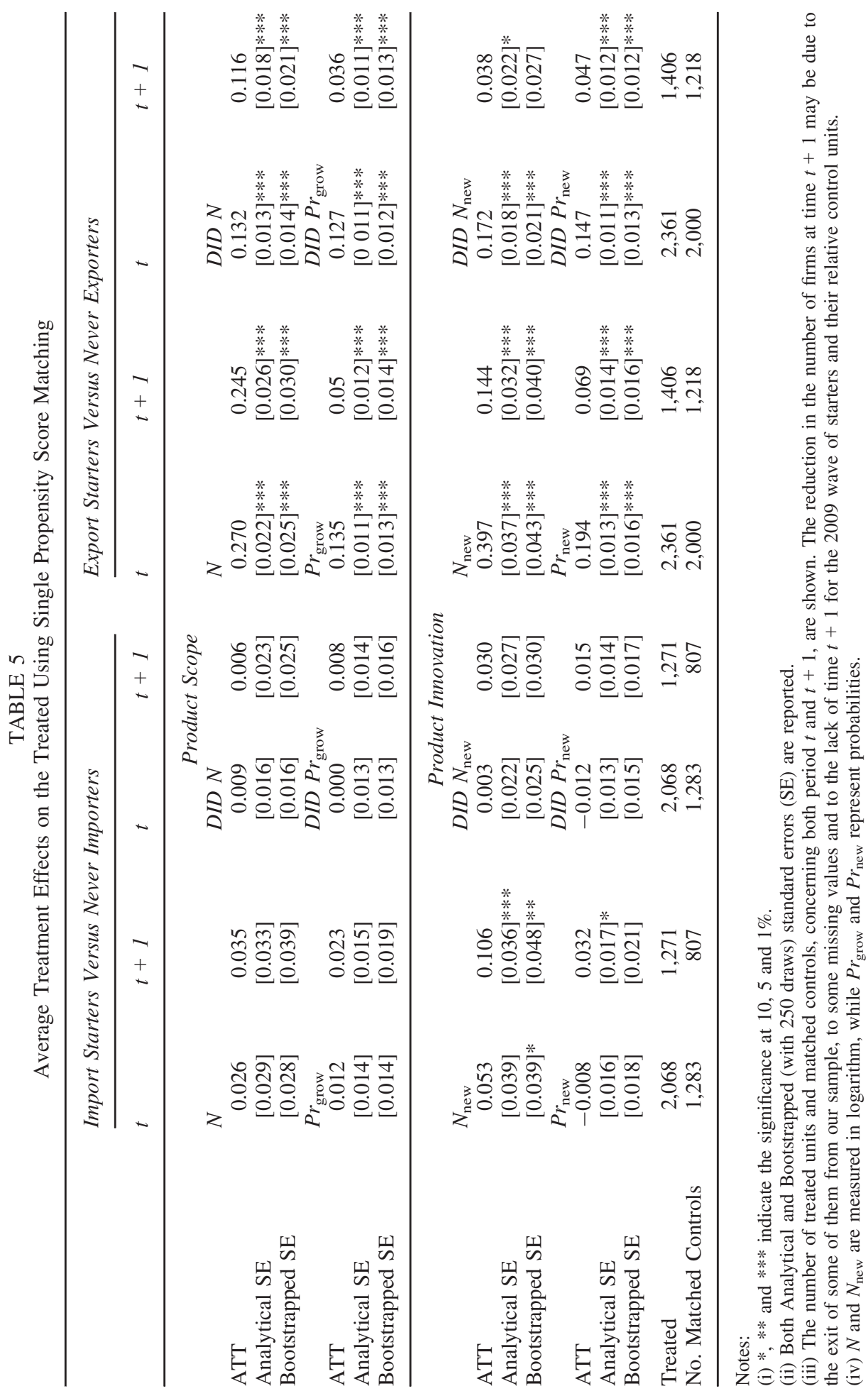


While reinforcing the evidence on exporting, SPSM reveals a mild role of imports for product innovation that, as previously shown, totally fades away in the MPSM setting. To check whether this evidence on importing derives from the lack of any control for the export start, we exclude export starters from the SPSM analysis of importing. It turns out that imports do not significantly affect firm product innovation. Thus, the mild significant impact found in the standard SPSM is driven by the presence of two-way trade starters in the sample of analysis. This set of results is not show for brevity and is available upon request.

Thus, MPSM turns out to be a superior empirical approach in the analysis of trade. Besides disentangling potential import-export complementarity effects, it allows for the isolation of the impact of each trade strategy thus preventing researchers from confounding their effects.

\section{c. Production to Order or Learning from Two-way Trading?}

The above findings stress the positive impact of exporting that is enhanced by the simultaneous involvement in the import activity. A possible interpretation of this evidence relies on the central role of Turkey in global supply chains. As a matter of fact, the export activity of manufacturing firms could be intimately related to imported inputs resulting from offshoring practices of foreign buyers in advanced countries. For Turkish firms, offshored productions can turn into new products which strongly depend on foreign inputs for their realisation. Then, compared to pure exporters, the trade premium in terms of new product lines could be rather amplified. This, however, raises a possible concern in the above interpretation of MPSM results, as the main findings on two-way traders could rather reflect production to order (PTO) phenomena than true learning by importing and exporting at the same time. This concern is reinforced by the findings of significant effects mainly in the entry year. ${ }^{15}$ In order to shed light on our main insight, we first check how many two-way starters are foreign owned. In our estimation, in the sample only one two-way starter is foreign owned. Nonetheless, PTO may well take place through contracts between foreign buyers and domestic firms. This offshoring typology is more widespread when the technological content of the production phases to develop abroad is low and, thus, it is more likely that in the Turkish economy, PTO occurs through arm's length contracts. To investigate further whether our results on two-way traders are driven by PTO, we run a PSM analysis by (i) comparing two-way starters to export starters that were already importing in $t$ and $t-1^{16}$ and (ii) comparing export starters that purchase a new imported input in $t$ to export starters-continuous importers that do not add any new foreign input in $t \cdot{ }^{17}$ Statistically significant differences between treated and control groups would imply that the above MPSM results are mainly driven by PTO, rather than by learning by the joint involvement in both trade strategies. As in Table 6, no statistically significant effect emerges, and we are more confident about our former interpretation.

\footnotetext{
15 We are extremely grateful to an anonymous referee for having suggested this line of inquiry.

16 Results do not change when continuous importers over the whole period starting to export are considered as control group.

17 New foreign inputs are those imported products that a firm imports in $t$ and has never imported before. However, we also define a new imported input in a more stringent way as a Turkish firm's purchase of a new foreign input that has never been imported before in the whole country. No differences emerge from the adoption of the two definitions; nonetheless, we prefer to stick to the former because in our view, it is more suitable to investigate the PTO hypothesis.
} 


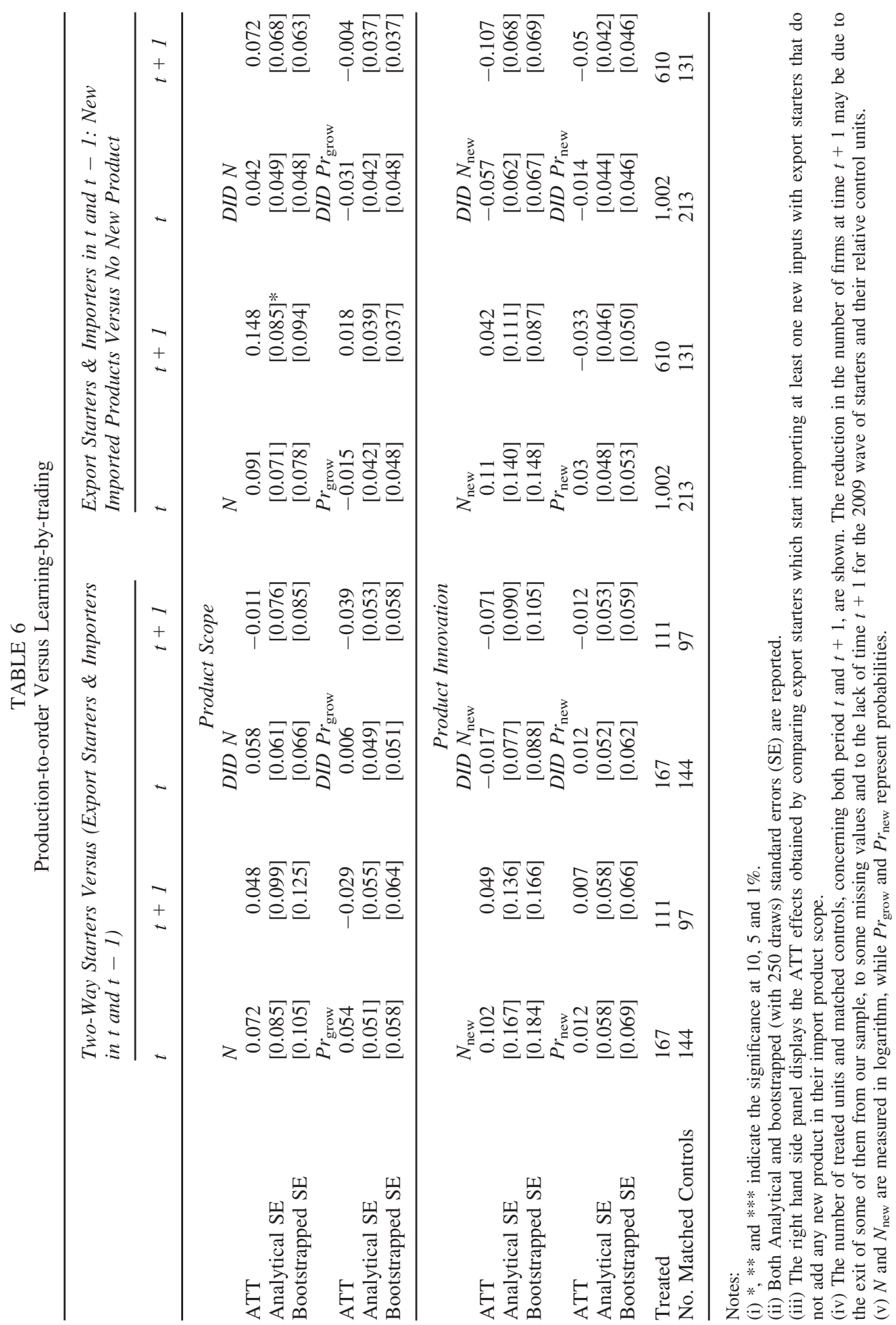


The lack of a persistent effect of two-way trading on product innovation could then follow from firms' product portfolio choices. Firms could avoid introducing new products frequently, so as not to cannibalise their own existing products. In line with this hypothesis, in our sample, only 25 per cent of firms introducing a product innovation in $t$ introduces another new product in $t+1$. Nevertheless, we cannot exclude that the possible learning process, at work after entry, is not properly captured by the small size of our sample in $t+1$.

\section{d. Inspecting the Extent and Nature of Product Innovation}

To further qualify the implications of our analysis, we extended our investigation to further variables capturing the quantitative and qualitative nature of product innovation. Thus, to assess the importance of the firm's innovative efforts for its production activity, we estimate the impact of firm trade strategies on the share of new products over total firm product scope, Share ${ }_{\text {new }}^{N}$, and on the production share from new products, Share $e_{\text {new }}^{\text {Prod }}$. Also, to gather some insights into the quality level of new products compared with the existing ones (Verhoogen and Kugler, 2012; Fernandes and Paunov, 2013), we inspect a dummy, $\operatorname{Pr}_{\text {new }}^{\text {High }}$, capturing the introduction of new products with a higher unit value than the old ones. MPSM results in Table 7 emphasise the importance of export activity in enhancing the weight of newly introduced products in firm production and product portfolio, while starting to import reinforces the positive effects of export entry. Turning to the relative quality of new products, two-way traders are more likely to introduce higher quality new goods. It also emerges that starting to export has a mild effect on the probability to start introducing higher quality new goods the year after the entry.

This evidence, thus, reveals that exporting and the simultaneous involvement in exporting and importing could particularly favour a country's development pattern. These trade strategies, indeed, may be effective in pushing manufacturing production towards a higher sophistication level.

\section{e. Robustness Checks}

We implemented a number of sensitivity checks to prove the robustness of our findings. First, the validity of the bootstrapping approach for the computation of standard errors in the NN matching has been criticised by Abadie and Imbens (2008) who claim that only subsampling standard errors would deliver unbiased estimates. Thus, for our baseline results, we computed subsampling based standard errors, relying on subsamples representing 70 per cent of the original sample size and performing 250 replications. Second, the estimation of the multinomial logit for the recovery of the propensity scores relies on the independence of irrelevant alternatives hypothesis. This hypothesis may be strong in our framework since it implies that, in the choice between two trade strategies, firms do not consider the other available options at all. We then relaxed this assumption by estimating a mixed logit model. Third, we tested the sensitivity of our analysis to an alternative definition of produced exports - and of exporter status - by matching 12-digit trade flows with the production data defined at the more aggregate 6-digit CPA classification. ${ }^{18}$

${ }^{18}$ We also tested more aggregate matching levels. This set of results is available from the authors. 


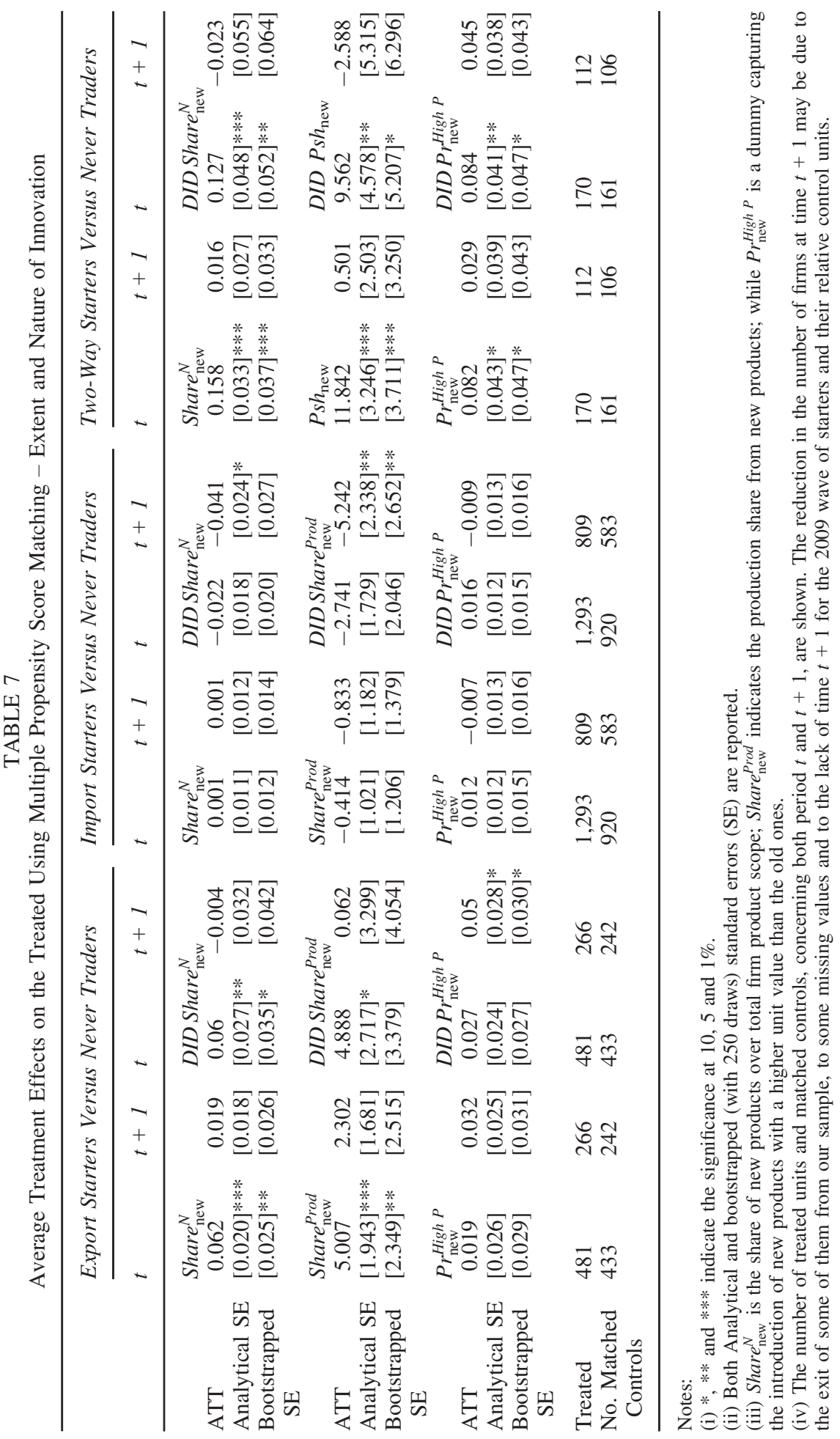


TABLE 8

Robustness Checks

\begin{tabular}{|c|c|c|c|c|c|c|}
\hline \multirow[t]{2}{*}{ Outcome } & \multicolumn{2}{|c|}{$\begin{array}{l}\text { Export Starters Versus } \\
\text { Never Traders }\end{array}$} & \multicolumn{2}{|c|}{$\begin{array}{l}\text { Import Starters } \\
\text { Versus Never } \\
\text { Traders }\end{array}$} & \multicolumn{2}{|c|}{$\begin{array}{l}\text { Two-way Starters } \\
\text { Versus Never Traders }\end{array}$} \\
\hline & $t$ & $t+1$ & $t$ & $t+1$ & $t$ & $t+1$ \\
\hline \multicolumn{7}{|l|}{ Subsample SE } \\
\hline \multicolumn{7}{|c|}{ Product Scope } \\
\hline$N$ & $0.179 * * *$ & $0.137 *$ & -0.005 & -0.001 & $0.230 * *$ & $0.297 * *$ \\
\hline DID $N$ & $0.094 * * *$ & 0.077 & 0.003 & 0.011 & $0.147 * *$ & $0.154^{*}$ \\
\hline$P r_{\text {grow }}$ & $0.060 *$ & 0.019 & 0.019 & 0.006 & $0.153 * * *$ & 0.080 \\
\hline DID $P r_{\text {grow }}$ & $0.081 * * *$ & 0.026 & 0.019 & 0.005 & $0.153 * * *$ & 0.063 \\
\hline \multicolumn{7}{|c|}{ Product Innovation } \\
\hline$N_{\text {new }}$ & $0.204 * *$ & 0.045 & -0.008 & 0.064 & $0.447 * *$ & 0.107 \\
\hline DID $N_{\text {new }}$ & 0.089 & 0.029 & -0.015 & -0.016 & $0.179 *$ & 0.011 \\
\hline$P r_{\text {new }}$ & $0.091 * *$ & 0.056 & 0.001 & 0.000 & $0.224 * * *$ & 0.045 \\
\hline DID $P r_{\text {new }}$ & $0.098 * * *$ & 0.064 & -0.008 & -0.010 & $0.182 * * *$ & 0.062 \\
\hline \multicolumn{7}{|l|}{ Mixed Logit } \\
\hline \multicolumn{7}{|c|}{ Product Scope } \\
\hline$N$ & $0.251 * * *$ & $0.208 * * *$ & -0.022 & -0.014 & $0.204 * *$ & $0.225^{* *}$ \\
\hline DID $N$ & $0.107 * * *$ & 0.039 & -0.015 & -0.012 & $0.114 * *$ & $0.150^{* *}$ \\
\hline$P r_{\text {grow }}$ & $0.104 * * *$ & 0.008 & -0.009 & -0.009 & $0.106 * *$ & 0.053 \\
\hline DID $P r_{\text {grow }}$ & $0.104 * * *$ & 0.020 & -0.003 & -0.001 & $0.106^{* *}$ & 0.053 \\
\hline \multicolumn{7}{|c|}{ Product Innovation } \\
\hline$N_{\text {new }}$ & $0.245 * * *$ & -0.004 & -0.003 & 0.044 & $0.412 * * *$ & 0.071 \\
\hline DID $N_{\text {new }}$ & $0.086^{*}$ & -0.05 & -0.024 & -0.035 & $0.138^{*}$ & 0.015 \\
\hline$P r_{\text {new }}$ & $0.162 * * *$ & 0.012 & -0.014 & 0.001 & $0.141 * * *$ & 0.009 \\
\hline DID $P r_{\text {new }}$ & $0.120 * * *$ & 0.031 & -0.015 & -0.014 & $0.112 * *$ & 0.018 \\
\hline \multicolumn{7}{|c|}{ Alternative definition of produced exports } \\
\hline \multicolumn{7}{|c|}{ Product Scope } \\
\hline$N$ & $0.242 * * *$ & $0.159 * *$ & 0.003 & 0.010 & $0.168 *$ & $0.196^{*}$ \\
\hline DID $N$ & $0.087 * * *$ & -0.004 & -0.008 & 0.004 & $0.088^{*}$ & 0.096 \\
\hline$P r_{\text {grow }}$ & $0.101 * * *$ & -0.021 & -0.019 & -0.015 & $0.109 * *$ & 0.034 \\
\hline DID $P r_{\text {grow }}$ & $0.084 * * *$ & -0.018 & -0.022 & -0.028 & $0.082 *$ & 0.051 \\
\hline \multicolumn{7}{|c|}{ Product Innovation } \\
\hline$N_{\text {new }}$ & $0.249 * * *$ & -0.035 & -0.004 & 0.056 & $0.304 * *$ & 0.009 \\
\hline DID $N_{\text {new }}$ & 0.059 & -0.096 & -0.035 & -0.045 & $0.170 * *$ & 0.037 \\
\hline$P r_{\text {new }}$ & $0.128 * * *$ & -0.014 & -0.011 & 0.008 & $0.174 * * *$ & 0.034 \\
\hline DID $P r_{\text {new }}$ & $0.119 * * *$ & -0.050 & -0.023 & -0.022 & $0.147 * * *$ & 0.060 \\
\hline \multicolumn{7}{|c|}{ Starters' definition based on both $t-1$ and $t-2$} \\
\hline \multicolumn{7}{|c|}{ Product Scope } \\
\hline$N$ & $0.300 * * *$ & $0.235 * *$ & -0.008 & 0.043 & $0.268^{* *}$ & 0.217 \\
\hline DID $N$ & $0.166^{* * *}$ & $0.141^{* *}$ & -0.016 & 0.002 & 0.09 & 0.028 \\
\hline$P r_{\text {grow }}$ & $0.148 * * *$ & 0.068 & -0.007 & 0.002 & $0.148 * *$ & 0.021 \\
\hline DID $P r_{\text {grow }}$ & $0.142 * * *$ & 0.049 & -0.005 & -0.004 & $0.102 *$ & 0.000 \\
\hline \multicolumn{7}{|c|}{ Product Innovation } \\
\hline$N_{\text {new }}$ & $0.406^{* * *}$ & 0.093 & -0.019 & 0.048 & $0.443 * * *$ & 0.167 \\
\hline DID $N_{\text {new }}$ & $0.151 * * *$ & 0.012 & -0.004 & 0.015 & $0.211 * *$ & 0.060 \\
\hline
\end{tabular}


TABLE 8 Continued

\begin{tabular}{|c|c|c|c|c|c|c|}
\hline \multirow[t]{2}{*}{ Outcome } & \multicolumn{2}{|c|}{$\begin{array}{l}\text { Export Starters Versus } \\
\text { Never Traders }\end{array}$} & \multicolumn{2}{|c|}{$\begin{array}{l}\text { Import Starters } \\
\text { Versus Never } \\
\text { Traders }\end{array}$} & \multicolumn{2}{|c|}{$\begin{array}{l}\text { Two-way Starters } \\
\text { Versus Never Traders }\end{array}$} \\
\hline & $t$ & $t+1$ & $t$ & $t+1$ & $t$ & $t+1$ \\
\hline$P r_{\text {new }}$ & $0.184 * * *$ & 0.049 & 0.003 & 0.002 & $0.261 * * *$ & 0.083 \\
\hline DID $P r_{\text {new }}$ & $0.148 * * *$ & 0.031 & 0.003 & -0.009 & $0.193 * * *$ & 0.063 \\
\hline
\end{tabular}

Notes:

(i) The significance is based on Bootstrapped standard errors (250 draws).

(ii) Subsample SE: Subsampling based standard errors are reported by drawing subsamples which represent $70 \%$ of the original sample size and by performing 250 replications.

(iii) Mixed Logit: Propensity scores exploited in the multiple propensity score matching (MPSM) implementation are retrieved by estimating a mixed logit model instead of a multinomial logit.

(iv) Alternative definition of produced exports: The MPSM is implemented by making use of the firm status of exporting own produced goods defined according to the CPA/GTIP correspondence table.

(v) Starters' definition based on both $t-1$ and $t-2$ : In the MPSM implementation, export (import) starters are defined as those firms exporting (importing) at time $t$ but not exporting (importing) at time $t-1$ and at time $t-2$. (vi) $*, * *$ and $* * *$ indicate the significance at 10,5 and $1 \%$.

Finally, we used a stricter definition of export (import) starters focusing on those firms exporting (importing) at time $t$ but not exporting (importing) at time $t-1$ and at time $t-2$. Results obtained by implementing these controls are reported in Table 8 and mainly confirm our baseline findings.

Finally, it is worth mentioning that our results are robust to several further checks that we do not report here for brevity. To test for the change in the sample construction: (i) we defined product innovation at the more aggregated 8-digit PRODCOM and 6-digit CPA level; (ii) we excluded from the analysis the 2009 crisis year; (iii) we excluded firms from the Short Term Business Statistics (STS) which are collected in a different survey than AIPS. To further test our empirical approach: (i) we extended and changed the set of covariates in the multinomial logit specifications by including dummies for investors in tangible assets, for investors in intangible assets, for subcontractors and for outsourcers, by excluding firm output and by adding product scope and labour productivity growth at time $t-1$; (ii) we implemented matching by 2-digit NACE sector and year; (iii) we implemented the Kernel matching procedure instead of the NN matching; and (iv) we estimated propensity scores by means of a biprobit model.

\section{SUMMARY OF THE FINDINGS AND DISCUSSION}

All in all, our evidence highlights that exporting has a prominent role for firm product innovation both at the extensive and intensive margins. Indeed, exporters introduce a higher number of new products whose average quality is higher than the existing firm product basket. These two effects drive the positive impact of exporting on new products' share in firm production. $^{19}$

${ }^{19}$ Our findings on causality running from exporting to product innovation are also supported by the lack of evidence on the opposite nexus in Turkish manufacturing (Lo Turco and Maggioni, 2013b). 
Our analysis thus extends previous evidence on the positive effect of exporting on product innovation highlighted for advanced countries (Salomon and Shaver, 2005; Hahn and Park, 2011; Bratti and Felice, 2012) to the case of an emerging economy. However, our definition of export treatment is different as it only concerns produced exports. Actually, when we define export treatment in a broader way by including export of non-produced goods - reflecting firms' activity as a trade intermediary - the positive impact of exports is relevantly downsized. $^{20}$ This suggests that export contribution to product innovation estimated by previous works could be underestimated.

Furthermore, the lack of any significant impact of firm level imports on the firm product scope, and innovation is at odds with firm and sector level evidence found by Goldberg et al. (2009) and Colantone and Crinò (2014), respectively. Several explanations could lie behind this contrasting evidence.

First of all, while we focus on firm level import effects, the sector aggregation level of foreign input access measures in the two works could actually deliver different insights. When, as in the cited works, intrasector imports/tariffs are included in the computation of imported inputs or input tariffs, sector level measures could capture product innovation or product scope changes stemming from competition hitting firms producing inputs within the broadly defined sector.

Second, none of the two works specifically explores the simultaneous causal impact of exports.

Third, we cannot discard the fact that different effects can originate from different institutional and economic contexts and from different time spans of the three analyses. While Colantone and Crinò (2014) deal with a panel of advanced economies in the 1995-2007 period and Goldberg et al. (2009) explore the case of Indian liberalisation between 1989 and 1997, our work concerns the Turkish economy in very recent years. At the beginning of our sample time span (2005), Turkey was already a globally integrated economy, whose customs union with the EU in 1995 had already importantly shaped its foreign market participation. In this respect, imports could have played a role in the very beginning of the country's integration process when the internal market manufacturing inputs supply capacity was rather constrained. Finally, new imported inputs could require some time to effectively impact on firms' product baskets, and the limited time span at our disposal could prevent us from disclosing such an effect.

Although we cannot exclude that a more suitable data span or sample period could reveal a positive effect of the pure import strategy for Turkish firms as well, our work unambiguously points at foreign buyers representing a transmission channel for new production techniques and new technologies that turn into new products. The lack of convincing evidence on PTOH supports the existence of learning by two-way trading. Importing thus reinforces the export innovation effect. This could stem from the novelty and/or higher technology content of imported inputs that allows for the production of new goods meeting foreign buyers' requests and tastes.

\section{CONCLUSION}

The availability of original data at firm-product level for Turkey allowed us to investigate in depth the causal impact of trade on the firm product scope and innovation in an emerging country context. Differently from previous literature, we consider importing and exporting in

${ }^{20}$ Results are not shown for brevity; nonetheless, they are available upon request. 
a complex multiple treatment framework which allows to assess and dissect their alternative and joint effect and the impact of the switch from one activity to the other.

Our main findings show that starting to export positively affects the product scope, the introduction of new products and the probability to innovate. We then confirm the prominence of the network a firm is involved in and, especially, of foreign customers in, directly or indirectly, fostering the competitiveness of upstream suppliers. The latter can both learn and benefit from technology, and knowledge transfers from their foreign buyers, but can also, irrespective of any direct request, develop new goods and introduce quality improvements and restyling of existing products to meet the preferences and needs of a foreign market. Also, an important complementarity exists between starting to import and to export, as we find that purchasing inputs abroad reinforces the positive effects of export entry. On the contrary, departing from existing evidence, we show that imports alone do not matter for product innovation.

This set of results proves fruitful in a number of ways. From a methodological point of view, we show that treating the firm internationalisation activities as isolated strategies may drive to misleading insights, as emerges from the comparison of MPSM and SPSM settings.

Although our evidence on exporting as the leading trade strategy for innovation is confined to Turkish manufacturing, this result echoes most of the previous findings in the literature and, thus, supports the general relevance of such activity for a country's growth pattern. Our original contribution is, however, to highlight the importance of the identification of a firm's own produced exports that appear as the main driver behind the trade-innovation nexus. This can explain the absence of any export effect in some papers focusing, instead, on the firm's overall export activity including also trading goods. It follows the need for a proper definition of exporting and for a more careful investigation of its effects.

Finally, our work demonstrates that the virtuous nexus between the two international activities, documented by the literature (Kasahara and Lapham, 2013), leads to an enhanced effect of the firm's joint export and import involvement on product innovation and quality upgrading.

Policy makers in emergent markets should then be concerned about easing the firm's entry in global supply chains, by targeting policies aimed at promoting home manufacturing abroad and at providing the firm with the necessary financial and technical tools to overcome national borders.

Two streams of future research spring from our work. On the one hand, under data availability, buyer-supplier relationships in international markets should be explored more in depth. On the other hand, it should be assessed to what extent trade-induced innovation provides a spin-off for the country's economic growth.

\section{REFERENCES}

Abadie, A. and G. W. Imbens (2008), 'On the Failure of the Bootstrap for Matching Estimators', Econometrica, 76, 6, 1537-57.

Bernard, A., E. Blanchard, I. van Beveren and H. Vandenbussche (2012), 'Carry-along Trade'. Working Paper 18246 (Cambridge, MA: National Bureau of Economic Research).

Blundell, R. and M. Costa Dias (2000), 'Evaluation Methods for Non-experimental Data', Fiscal Studies, 21, 4, 427-68.

Blundell, R. and M. Costa Dias (2009), 'Alternative Approaches to Evaluation in Empirical Microeconomics', Journal of Human Resources, 44, 3, 565-640.

Bratti, M. and G. Felice (2012), 'Are Exporters More Likely to Introduce Product Innovations?', The World Economy, 35, 11, 1559-98.

Caliendo, M. and S. Kopeinig (2008), 'Some Practical Guidance for the Implementation of Propensity Score Matching', Journal of Economic Surveys, 22, 1, 31-72. 
Colantone, I. and R. Crinò (2014), 'New Imported Inputs, New Domestic Products', Journal of International Economics, 92, 1, 147-65.

Damijan, J., C. Kostevc and S. Polanec (2010), 'From Innovation to Exporting or Vice Versa?', The World Economy, 33, 3, 374-98.

Egan, M. L. and A. Mody (1992), 'Buyer-Seller Links in Export Development'. World Development, 20, 3, 321-34.

Feenstra, R. C. (1994), 'New Product Varieties and the Measurement of International Prices', American Economic Review, 84, 1, 157-77.

Fernandes, A. and C. Paunov (2010), 'Does trade stimulate product quality upgrading?', Canadian Journal of Economics, 46, 4, 1232-64.

Goh, A. T. (2005), 'Knowledge Diffusion, Input Supplier's Technological Effort and Technology Transfer via Vertical Relationships', Journal of International Economics, 66, 2, 527-40.

Goldberg, P. K., A. Khandelwal, N. Pavcnik and P. Topalova (2009), 'Trade Liberalization and New Imported Inputs', American Economic Review, 99, 2, 494-500.

Hahn, C. H. and C. G. Park (2011), 'Direction of Causality in Innovation-exporting Linkage: Evidence From Microdata on Korean Manufacturing', Korea and the World Economy, 12, 2, 367-98.

Kasahara, H. and B. Lapham (2013), 'Productivity and the Decision to Import and Export: Theory and Evidence', Journal of International Economics, 89, 2, 297-316.

Lechner, M. (2001), 'Identification and Estimation of Causal Effects of Multiple Treatments Under the Conditional Independence Assumption', in: M. Lechner and F. Pfeiffer (eds.), Econometric Evaluation of Labour Market Policies (Heidelberg: Physica-Verlag), 1-18.

Lechner, M. (2002), 'Some Practical Issues in the Evaluation of Heterogeneous Labour Market Programmes by Matching Methods', Journal of the Royal Statistical Society Series A, 165, 1, 59-82.

Lo Turco, A. and D. Maggioni (2013a), 'CAT exports in Turkish Manufacturing'. Working Paper 662 (FREIT).

Lo Turco, A. and D. Maggioni (2013b), 'Dissecting the Impact of Innovation on Exporting in Turkey'. DISES Working Paper 388 (Ancona: Università Politecnica delle Marche).

Lo Turco, A. and D. Maggioni (2014), 'The Micro Evolution of Trade and Turnover in Turkey Under the Global Crisis'. Economic Systems, forthcoming, doi:10.1016/j.ecosys.2013.09.005.

Misch, F. and A. Seymen (2012), 'The Effects of Countercyclical Fiscal Policy: Firm-level Evidence from Temporary Consumption Tax Cuts in Turkey'. Discussion Paper 12-082 (Mannheim: ZEW).

Pamukcu, T. (2003), 'Trade Liberalization and Innovation Decisions of Firms: Lessons From Post-1980 Turkey', World Development, 31, 8, 1443-58.

Pierce, J. R. and P. Schott (2009), 'Concording U.S. Harmonized System Categories Over Time'. Working Paper 14837 (Cambridge, MA: National Bureau of Economic Research).

Puga, D. and D. Trefler (2010), 'Wake Up and Smell the Ginseng: International Trade and the Rise of Incremental Innovation in Low-wage Countries', Journal of Development Economics, 91, 1, 64-76.

Rauch, J. E. and J. Watson (2003), 'Starting Small in an Unfamiliar Environment', International Journal of Industrial Organization, 21, 7, 1021-42.

Salomon, R. M. and M. J. Shaver (2005), 'Learning by Exporting: New Insights From Examining Firminnovation', Journal of Economics \& Management Strategy, 14, 2, 431-60.

Uygur, E. (2010), 'The Global Crisis and the Turkish Economy'. TWN Economic Series 21. Available at http://www.twnside.org.sg/title2/ge/ge21.pdf (accessed 3 June 2014).

Van Beveren, I. and H. Vandenbussche (2010), 'Product and Process Innovation and Firms' Decision to Export', Journal of Economic Policy Reform, 13, 1, 3-24.

Verhoogen, E. and M. Kugler (2012), 'Prices, Plant Size, and Product Quality', Review of Economic Studies, 79, 1, 307-39.

Wagner, J. (2007), 'Exports and Productivity: A Survey of the Evidence From Firm-level Data', The World Economy, 30, 1, 60-82.

WTO (2012), 'Trade Policy Review of Turkey'. Report by the Secretariat (Geneva: World Trade Organisation). 
APPENDIX

TABLE A1

Balancing Tests

\begin{tabular}{|c|c|c|c|c|c|c|}
\hline & \multirow{2}{*}{$\begin{array}{l}\text { Treated } \\
\text { Firms }\end{array}$} & \multirow{2}{*}{$\begin{array}{l}\text { Control } \\
\text { Firms }\end{array}$} & \multirow{2}{*}{$\begin{array}{l}\% \text { Treated } \\
\text { Firms Out } \\
\text { of Support }\end{array}$} & \multicolumn{2}{|c|}{ Median Bias } & \multirow{2}{*}{$\begin{array}{l}\text { \% Drop } \\
\text { Bias }\end{array}$} \\
\hline & & & & Before & After & \\
\hline \multicolumn{7}{|l|}{ MPSM } \\
\hline Export Starters/Never Traders & 481 & 433 & 0.21 & 7.10 & 3.04 & 57.11 \\
\hline Import Starters/Never Traders & 1,293 & 920 & 0.15 & 6.93 & 1.54 & 77.76 \\
\hline Two-way Starters/Never Traders & 170 & 161 & 0.00 & 12.25 & 3.93 & 67.89 \\
\hline Two-way Starters/Export Starters & 165 & 123 & 2.94 & 8.75 & 4.81 & 45.09 \\
\hline Two-way Starters/Import Starters & 169 & 156 & 0.59 & 6.95 & 3.96 & 43.11 \\
\hline Import Starters/Export Starters & 1,244 & 365 & 3.94 & 10.93 & 6.41 & 41.38 \\
\hline \multicolumn{7}{|l|}{ SPMS } \\
\hline Export Starters/Never Exporters & 2,361 & 2,000 & 0.00 & 6.73 & 1.26 & 81.28 \\
\hline Import Starters/Never Importers & 2,068 & 1,283 & 0.67 & 7.29 & 1.74 & 76.10 \\
\hline
\end{tabular}

Notes:

(i) The covariate balancing tests for the multiple propensity score matching (MPSM) and single propensity score matching (SPSM) are shown in the upper and bottom panels, respectively.

(ii) Treated firms are in the common support if their propensity score is lower than the maximum and higher than the minimum score of the control units. (iii) In the columns (4) and (5) of the upper panel (bottom) we display the median bias across all the covariates included in the multinomial (probit) estimation before and after the matching for MPSM (SPSM). 